\title{
Uma visão helleriana da inserção social na EaD: Análise do cotidiano e da cotidianidade na formação de professores de Matemática em rede nacional (PROFMAT).
}

Une vision hellérienne de l'insertion sociale dans les EAD: Analyse de la vie quotidienne et de la vie quotidienne dans la formation des enseignants de mathématiques en réseau national (PROFMAT).

Una visión helleriana de la inserción social en EaD: Análisis de la vida cotidiana y la vida cotidiana en la formación de professores de Matemáticas en la red nacional (PROFMAT).

A Hellerian view of social insertion in EaD: Analysis of daily life and daily life in the formation of teachers of Mathematics in national network (PROFMAT).

Débora Gaspar Soares. e Márcio Rufino Silva.

\section{OpenEdition}

Journals

\section{Edição electrónica}

URL: http://journals.openedition.org/espacoeconomia/8070

DOI: $10.4000 /$ espacoeconomia.8070

ISSN: 2317-7837

Editora

Núcleo de Pesquisa Espaço \& Economia

Refêrencia eletrónica

Débora Gaspar Soares. e Márcio Rufino Silva., « Uma visão helleriana da inserção social na EaD:

Análise do cotidiano e da cotidianidade na formação de professores de Matemática em rede nacional (PROFMAT). », Espaço e Economia [Online], 15 | 2019, posto online no dia 02 novembro 2019,

consultado o 05 novembro 2019. URL : http://journals.openedition.org/espacoeconomia/8070 ; DOI : 10.4000/espacoeconomia.8070

Este documento foi criado de forma automática no dia 5 novembro 2019.

(c) NUPEE 


\section{Uma visão helleriana da inserção social na EaD: Análise do cotidiano e da cotidianidade na formação de professores de Matemática em rede nacional (PROFMAT).}

Une vision hellérienne de l'insertion sociale dans les EAD: Analyse de la vie quotidienne et de la vie quotidienne dans la formation des enseignants de mathématiques en réseau national (PROFMAT).

Una visión helleriana de la inserción social en EaD: Análisis de la vida cotidiana y la vida cotidiana en la formación de professores de Matemáticas en la red nacional (PROFMAT).

A Hellerian view of social insertion in EaD: Analysis of daily life and daily life in the formation of teachers of Mathematics in national network (PROFMAT).

Débora Gaspar Soares. e Márcio Rufino Silva.

\section{Introdução.}

1 A formação de professores de Matemática em rede nacional (PROFMAT), em nossa investigação, pretende abarcar as tramas, as tranças, e as teias da conexão entre sociedade e educação em EaD e o seu ritmo. Dialogar entre o global e o sui generis, entre a escola-instituição formadora das relações sociais de produção capitalista e as profusas experiências possíveis da prática docente, que dão a conhecer profundas alteridades sócio espaciais, das quais se assemelham a uma travessia indefinidamente em alomorfia. Da mesma maneira essas alteridades quando se tenta fazer o elo, o link, essas revelam silhuetas, sombras, contornos, formas descontínuas, perfis variados, diversas escalas que em rede (o lugar, o regional, o nacional, o global) 'tangenciam o aspecto 
geográfico da sua formação. Como estabelece Heller (2016 [1970], p. 14): “a indignação e a rebelião elementares da humanidade contra o fascismo fornecem a prova mais cabal daquilo que chamamos de invencibilidade da substância humana". A autora esclarece a dificuldade de se estudar a escola, tal interpretação integra, sobretudo, a formação para professores de Matemática em rede nacional (PROFMAT), exige um olhar vigilante na percepção de estrutura para formação social, porque distingui que a escola está hierarquicamente tomada como lugar de domínio estatal, e que reflete ativamente como organismo de controle, por isso os "valores" da escola são sim, determinadas pela ideologia do capital e da vivência escolar das pessoas que lá participam. Devido essa exigência que esse estudo prioriza a bibliografia teórica de Agnes Heller, porque encontra condições propícias para compreender com o processo histórico, o cotidiano e cotidianidades: problematizações e mediações necessárias, em especial para pesquisa em formação em EaD.

2 O que torna a leitura de Agnes Heller fundamental para um estudo rigoroso sobre as contemporâneas transformações que a inovação corresponde para a formação de Professores em Matemática em rede nacional (PROFMAT) é sua teoria marxista crítica, sua biografia permite investigar o espaço social escolar como instituição, mas percebendo a presença, a ação, a atividade das pessoas, do sujeito indivíduo, do sujeito social, que na formação EaD se conecta, e tece redes sociais no seu cotidiano.

3 Para realização e análise das transformações que a inovação corresponde para a formação de Professores em Matemática em rede nacional (PROFMAT), as alteridades sócio espaciais, com o ambiente laboral, e com a compreensão de mais valia há uma variedade de teóricos que alteia esse debatimento (Marx, 1983 [1867]; Silva, 2008; Damiani, 2016; Heller, 2016 [1970]; Lukács, 2003; Lefebvre, 1991; entre outros), dentre outras bibliografias pertinentes para o desenvolvimento desse trabalho. Além da bibliografia desses teóricos foi imprescindível o curso nas disciplinas: Epistemologia da Geografia, ministrada pelo Professor Guilherme Ribeiro; e A (Re)produção do Espaço e Cotidiano: Escalas do Urbano e sua Mobilização Crítica, ministrada pelo Professor Márcio Rufino. Essas disciplinas fazem parte do curso de Pós-Graduação em Geografia, e oportunizam o debate e entendimento da dinâmica do processo histórico no exercício das transformações e reproduções no espaço cotidiano. Foram realizadas com encontros presenciais, no prédio da Geociências, Departamento de Geografia em Seropédica no segundo semestre de 2018.

\section{Entre links e comunicação, conforme Agnes Heller admite o contato em territórios virtuais.}

4 As discussões e argumentações relativas à renovação e formação das competências e habilitações do corpo social contemporâneo, circunscrevem os processos históricos e a premência social dos fatos, mas precisam criticar as conjunturas de produção capitalista, o acesso distinto a escola, e o arcabouço institucional que subjuga os seus participantes. Por isso, compreender a correlação entre saber e o poder presume assentir que uma implementação de política educacional, que requer a estruturação da inovação na sociedade presente é razão e circunstância para a reprodução material dessa forma de trabalho na sociedade. Em outros termos, o meio de produção capitalista depreende uma conformação de organização do saber que não é apenas retrato da vida escolar, essa não reflete nitidamente sobre os distintos protagonistas da 
vida na escola. Segundo Heller (2016 [1970], p.15): "podemos estabelecer a possibilidade de um subsequente desenvolvimento dos valores, apoiar tal possibilidade e, desse modo, emprestar um sentido à nossa história." Em conformidade Lefebvre (1991, p.8) diz: "o tempo é o tempo da mudança. Não aquele de uma simples modificação local, parcial, mas o tempo das transições e dos transitórios, o dos conflitos; da dialética e do trágico." Já Luckacs (2003, p. 205) afirma que: "o tempo é tudo, o homem não é mais nada; quando muito, é a personificação do tempo." Esses autores tornam claro que a análise do ordinário da vida, do cotidiano, fundamenta as questões, as indagações sobre as mudanças e transformações atuais na educação com o uso da inovação, determinadas pela elucubração econômica e pela influência cultural.

5 Os estudos acerca do Ensino a Distância no Brasil demandam uma exploração sobre o seu território, para conhecer a rede que se compõe apoiada na sua oferta. Nesse ínterim, a caracterização de rede está relacionada à circulação e alastramento da informação e conhecimento. Entretanto, os territórios virtuais na educação determinam a validação dos conhecimentos, e o contato virtual demarca quais pessoas podem ou não articular as práticas pedagógicas a eles relacionadas. Ocorre uma inibição da prática pedagógica, a manifestação do diálogo aberto é restringida. Contudo, qual é a ameaça da prática pedagógica para o professor? o maior risco da prática pedagógica é a reflexão, o que isso quer dizer? A reflexão acontece no diálogo, no confronto, e a prática pedagógica é também responsável pelas representações do sujeito como indivíduo, pois ela traz memórias, técnicas, recursos, maneiras de experienciar, formas de viver, ritmando as alteridades sociais que a alicerçam. Conforme Heller (2016 [1970], p.17) destaca: "a· vida cotidiana é a vida do homem inteiro; ou seja, o homem participa na vida cotidiana com todos os aspectos de sua individualidade, de sua personalidade." A autora esclarece que a ameaça da prática pedagógica se desvalia na regulamentação das ações, no controle, no interdito, nos critérios, nos conteúdos, pois são definidos, eminentemente, por aqueles que regem as instituições, com critérios, mecanismos e processos para reconhecimento como verdade superior, e como valorização do professor. Portanto, as conexões em rede tornam complexa a presença dos territórios virtuais e a sua vinculação com a educação.

6 O uso de inovação no cotidiano presume o incremento do território virtual, mas o processo de construção do espaço ocorre por múltiplas escalas, à geografia da inovação propende para o universal, ao invés do local, assim, o contato na rede adquiri, cada vez mais, pujança na vida cotidiana. $\mathrm{O}$ advento da internet rompeu limites físicos, o ritmo das informações é de imediatismo, acelerado, célere e extrapola as demarcações espaciais. As atividades humanas na sociedade informacional acontecem na rede, nela que se conectam diversas atuações no espaço, inclusive a educação. De acordo com Heller (2016 [1970], p.17): 'O homem da cotidianidade é atuante e fruidor,' ativo e receptivo, mas não tem nem tempo nem possibilidade de se absorver inteiramente em nenhum desses aspectos; por isso, não pode aguçá-los em toda sua intensidade.” A autora elucida que o homem moderno se organiza no território virtual através da rede, mas o ritmo acelerado das conexões não possibilita o planejamento, a superação de limites e de desafios desse cotidiano.

7 O ofício da escola é metamorfosear a prática pedagógica, que é difusa, variada, que sobrepuja algumas temáticas em detrimento de outras, e essa valorização de alguns conteúdos caracteriza um aspecto relevante do disciplinamento. A escola busca apresentar uma realidade como possibilidade única de percepção, a interpretação da 
verdade necessita pertencer à universidade como validação da ciência, com critérios, normas e regulações que prevalecem como superior. Os saberes dos professores para serem elevados a campo científico precisam da observação, experimentação, e análise fundamentada pela ciência. Ainda assim, os desenvolvimentos gradativos das histórias das pessoas envolvidas na escola, suas especificidades, sua vida comum, suas escolhas e ações cotidianas são reflexos e referências teóricas do processo histórico delineado por todos e todas que se conectam através da rede, nesse território virtual, nessa escola. Consoante à afirmação de Heller (2016 [1970], p.18): “O homem nasce já inserido em sua cotidianidade. $\mathrm{O}$ amadurecimento do homem significa, em qualquer sociedade, que o indivíduo adquire todas as habilidades imprescindíveis para a vida cotidiana da sociedade (camada social) em questão. É adulto quem é capaz de viver por si mesmo a sua cotidianidade." De acordo com Lukács (2003, p.208): “toda sociedade está submetida, ou pelo menos tende, a um processo econômico uniforme, e de que o destino de todos os membros da sociedade é movido também por leis uniformes." Já Lefebvre (1991, p.19) explicita que: "tudo o que se verifica parece pertencer ao universo, em que o mundo é encarado e enfrentado como a soma das coisas?" Para esses teóricos é muito importante para a sociedade informacional reinterpretar o sujeito, o lugar e as práticas pedagógicas que negligenciam a distinção de classes sociais na escola.

Uma percepção meritória que consegue coadjuvar na análise da relação da prática pedagógica e saberes dos professores observa a noção de que, para se engendrar, a prática pedagógica qualificada precisa se converter em desqualificada todas as outras práticas e sujeitos. O nosso cotidiano informacional está repleto de normatizações para o bem-estar que nos indicam como cuidar da saúde, alimentação, dos filhos, etc. A vida cotidiana já é determinada e direcionada por essas normas que a sociedade vai atualizando com o tempo, eximindo dos sujeitos o discernimento, a razão, a consciência e a destreza das suas escolhas. Como Heller (2016 [1970], p.18) aponta: "O homem aprende no grupo os elementos da cotidianidade (por exemplo, que deve levantar e agir por sua conta; ou o modo de cumprimentar, ou ainda como comportar-se em determinadas situações, etc.)." A autora elucida que uma prática pedagógica necessita se comunicar com todos e todas. Ora, como uma tradição, uma norma de vida deve ser considerada com o seu tempo histórico, assim uma prática pedagógica não deve ser representada por determinada classe social. A prática pedagógica deve dialogar e expressar as carestias de outros estratos sociais (mulheres, jovens, minorias raciais, etc.) que os correspondem.

No cenário dos territórios virtuais, os muros para a prática pedagógica na EaD se apresentam na multifuncionalidade do profissional, na precarização da função de tutor, na falta de exigência de formação de Tutores em EaD para explorar o uso da Plataforma educacional e para exercer a função de tutor, na condição temporária para exercer a função de tutor, no salário, entre tantos outros, que desqualificam o professor. De acordo com a Portaria Normativa №17, de 28 de dezembro de 2009, § 1": “O corpo docente do curso deve ser altamente qualificado, conforme demonstrado pela produção intelectual constituída por publicações específicas, produção artística ou produção técnico-científica, ou ainda por reconhecida experiência profissional, conforme o caso." O uso de inovação na educação, a prática pedagógica ser realizada através da rede, acontece com um acentuado critério técnico, rigorosamente sujeitado a políticas educacionais fomentadas com o apoio do capitalismo neoliberal. Concretizam-se na rede pela hierarquização e rigidez das disciplinas, que presumem o despreparo do tutor 
em reflexionar e compor práticas pedagógicas de maneira autônoma. Infelizmente, o uso de inovação na educação manifestou sutis e rebuscadas formas de domínio, que inibem e refreiam a prática pedagógica. Como Heller (2016 [1970], p.22) indigita: "o desenvolvimento do indivíduo é antes de mais nada - mas de nenhum modo exclusivamente - função de sua liberdade fática ou de suas possibilidades de liberdade." A autora observa que o ordinário da vida do homem seus sentimentos, paixões, crenças, ideologias e ideias engendram o exercício de todos os seus sentidos, aptidões, talentos, saberes e práticas.

10 Por que investigar o contato em territórios virtuais segundo Agnes Heller se a mesma não tratou da relação professor-aluno na sua biografia? A sua teoria marxista crítica supera as interpretações doutrinárias que professam o funcionalismo escola-sociedade, e é conveniente para perceber a escola como instituição, indispensável para analisar o sujeito contemporâneo nas redes sociais. Nesse sentido, o contato em territórios virtuais por Agnes Heller inclui a vida cotidiana com todas as suas formas, ações, vertentes, sentidos e perspectivas. No entanto, a inovação que faz parte da vida cotidiana, há prestação de serviços que não sobrevivem sem o uso da internet, e ainda assim, o seu uso na prática pedagógica e na comunicação exercida na rede pelas plataformas educacionais é rígido, os conteúdos condensados, as disciplinas hierarquizadas sem a possibilidade de criação e de implementação do tutor, o seu uso é estrito e definido e por isso restringe a dinâmica e a comunicação dos participantes. A inovação na prática pedagógica necessita aquiescer o movimento do participante ao invés de apenas agilizar informação; oportunizar o diálogo, explicitação, e compartilhamento de ideias ao invés de avivar redes sociais. Ora, se com a inovação não há movimento e não há deslinde, então essa prática pedagógica conduz a alienação da vida cotidiana. Em conformidade com Heller (2016 [1970], p.20): “A vida cotidiana é a vida do indivíduo. O indivíduo é sempre, simultaneamente, ser particular e ser genérico." A autora explica que o sujeito na vida cotidiana que apenas elabora e reelabora o conteúdo, ou o trabalho que lhe é proposto; apenas a sua nota, ou a sua parte, deteriora, dilapida e cerceia seu aspecto humano-genérico.

11 O que Agnes Heller coadjuva para um estudo rigoroso sobre as contemporâneas transformações que a inovação corresponde para a formação de Professores em Matemática em rede nacional (PROFMAT)? Para perfazer o que foi discutido sobre sua teoria marxista crítica, na sociedade humano-digital, o sujeito usa a inovação, mas aniquila e desfaz a sua objetividade, então, esse sujeito se escraviza a um retalho de realidade, encerra a sua espontaneidade, o sujeito escravo não participa do imprevisto, nem do improviso, ao alienar-se suas ações propendem para particularidade. Há uma profunda ausência de consciência da ação do sujeito alienado gerando uma voragem fronte a criação do sujeito genérico, e isso que caracteriza a conjuntura dessa alienação. Em concordância com Heller (2016 [1970], p.20): "Os choques entre particularidade e generosidade não costumam tornar-se conscientes na vida cotidiana; ambas se submetem sucessivamente uma à outra do aludido modo, ou seja, "mutuamente". A autora salienta que essa voragem não alcança de forma equivalente os diversos estratos sociais num processo histórico, entretanto agravou-se exponencialmente no capitalismo neoliberal. 


\section{Inserção Social para a formação de professores de Matemática em rede nacional (PROFMAT).}

A apresentação do Mestrado Profissional em Matemática em Rede Nacional (PROFMAT) se concebeu em 2011, por intermédio de uma rede de instituições de Ensino Superior, via constituição da Universidade Aberta do Brasil, fomentada por meio da Coordenação de Aperfeiçoamento Pessoal de Nível Superior (CAPES), e estruturada pela Sociedade Brasileira de Matemática (SBM), com a contribuição do Instituto Nacional de Matemática Pura e Aplicada (Impa). De acordo com o Relatório Digital PROFMAT (2017, p.1): "o PROFMAT surgiu mediante uma ação induzida pela CAPES junto à comunidade científica da área de Matemática, representada e coordenada pela SBM." As políticas públicas no sentido de usar a inovação estimularam o desenvolvimento de cursos de Graduação, Mestrados Profissionais, dentre outros orientados para a EaD, pelo sistema da Universidade Aberta do Brasil (UAB), com expansão da sua oferta e engajamento de diversas instituições públicas. Esse estudo vai analisar o polo do PROFMAT na Universidade Federal do Rio de Janeiro, que oferece o curso de Mestrado Profissional em Matemática em Rede Nacional no Estado do Rio de Janeiro desde a sua criação.

Figura 1: Número Total de vagas ofertas pelo PROFMAT (2011-2017)

\section{Número total de vagas ofertadas pelo PROFMAT (2011-2017). Fonte: SBM}

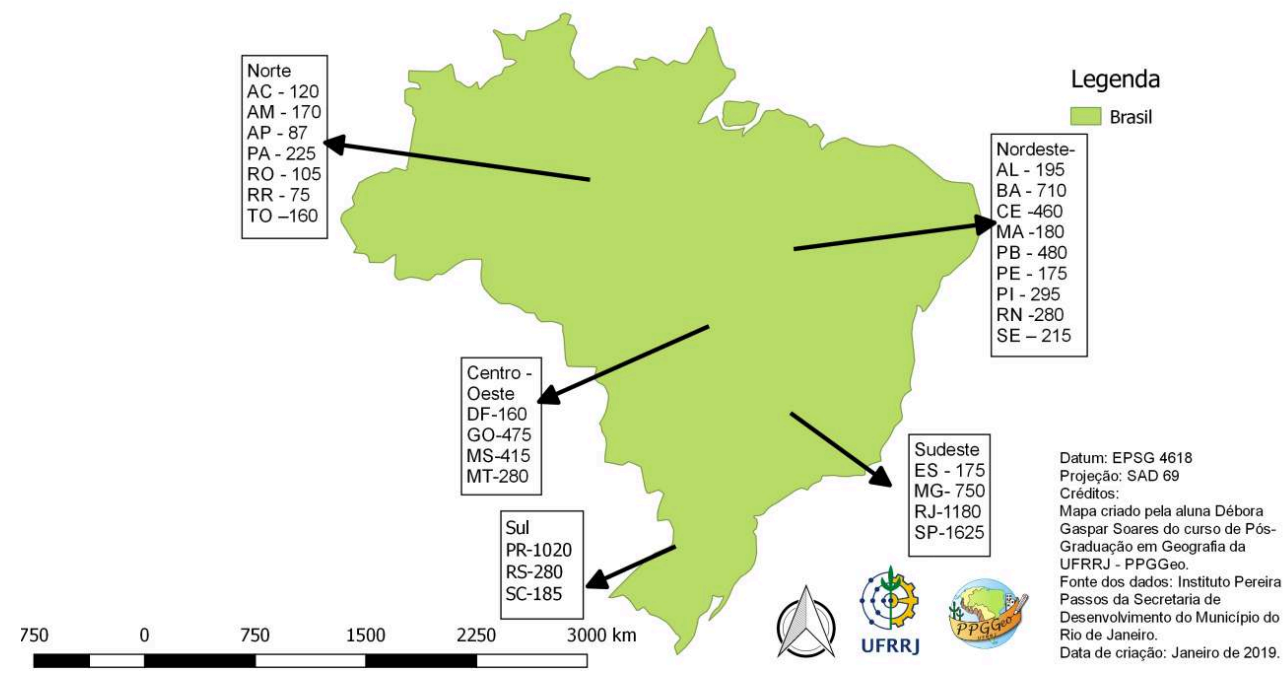

Fonte: Instituto Pereira Passos.

Para realizar esse estudo com relação à inserção social na EaD analisando como, em geral, se suscita o cotidiano e a cotidianidade na formação de professores de Matemática em rede nacional (PROFMAT), e compreendendo como, em particular, a teoria de Agnes Heller interpreta nossa sociedade informacional, onde prepondera o modo capitalista de produção. O primordial recurso foi o site do PROFMAT no qual foi pesquisado, especialmente, o Relatório Digital de 2017; Regimentos; Portarias e Designações. Em seguinte, foram realizadas entrevistas que ocorreram na Universidade Federal Rural do Rio de Janeiro, elas aconteceram no segundo semestre de 2018, com a 
Coordenação anterior e a atual Coordenação do PROFMAT, professores do ICE (Instituto de Ciências Exatas) que são membros do DEMAT (Departamento de Matemática da UFRRJ), essas que possibilitaram uma interação do ponto de vista das práticas produtivas, da ação cooperativa e das fontes de informação e conhecimento para inovação, respeitantes às características dessa amostra de estudo.

14 A efetivação, alastramento e promoção da inovação na prática pedagógica, por meio da rede em EaD, tipifica um arquétipo de inter-relação sócio espacial que reúne cidades como indicadores, que caracterizam os locais ou sítios, nos quais se organizam o contato, se criam as conexões, se formam as interações, que se geram pelos trânsitos de informações, e desenham um território virtual em rede. Destarte, a inovação no que se atribui a EaD, imputa uma expectativa social de ampliação e redimensionamento do lugar, de nova cartografia, de geração de novos caminhos, de criação de tecnologia, a partir de políticas públicas que fomentam o uso da rede nesse lugar. De acordo com Heller (2016 [1970], p.20): “o próprio cientista ou artista têm vida cotidiana: até mesmo os problemas que enfrentam através de suas objetivações e suas obras lhes são colocados, entre outras coisas (tão-somente entre outros, decerto), pela vida." Em conformidade Lukács (2003, p.215): "os instrumentos, as reservas, e os meios financeiros, indispensáveis tanto à empresa quanto à vida econômica, estão nas mãos do empresário, num caso, e do chefe político, no outro." Tal qual Damiani (2016, p.13) argumenta: "a industrialização envolve o imperativo do trabalho abstrato no campo e na cidade. Define-se como divisão social do trabalho, divisão campo-cidade. As relações sociais concorrenciais estruturam o fundamento das formas de sociabilidade modernas." Esses autores evidenciam que o uso da inovação promove uma interiorização em distintos graus de arquitetura de geografia das redes. E nos fazem refletir algumas questões: Para que o uso da EaD para promoção e formação técnicocientífica de Professores de Matemática? Como a rede projeta esse território virtual de práticas pedagógicas? Como o uso e difusão da rede na formação de Professores reverbera no ordenamento escolar das cidades desses professores?

$\mathrm{Na}$ conjuntura da sociedade informacional, a formação de Professores de Matemática em Rede Nacional adquire uma competência relevante na articulação do território do Município de Seropédica, local da Universidade Federal do Rio de Janeiro. Segundo Heller (2016 [1970], p.30): "a espontaneidade é a tendência de toda e qualquer forma de atividade cotidiana. A espontaneidade caracteriza tanto as motivações particulares (e as formas particulares de atividade) quanto às atividades humano-genéricas que nela têm lugar." A autora esclarece que a interação aluno-aluno, aluno-tutor, alunoprofessor, professor-tutor, tutor-tutor, pela rede perpassa pela espontaneidade de ambiência, aprendizagem, autonomia, comunicação e informação.

16 Esse polo presencial do PROFMAT adota a responsabilidade pela manutenção da sua infraestrutura para acolher e atender os alunos do curso, os professores que ministram as aulas são todos do DEMAT (Departamento de Matemática da Universidade Federal Rural do Rio de Janeiro), e os alunos têm acesso a Biblioteca, o Bandejão, Laboratório de Informática, salas de aula no Prédio Pitágoras, dentre outros que a Universidade Federal Rural do Rio de Janeiro disponibiliza. A tabela a seguir mostra os dados dos alunos regularmente matriculados no PROFMAT-UFRRJ, e permite analisar o alcance geográfico do PROFMAT ofertado pela UFRRJ. 
Tabela 1. Dados dos alunos regularmente matriculados no PROFMAT-UFRRJ (janeiro-2019).

\begin{tabular}{|l|l|l|l|l|}
\hline Municípios de Origem & Turma 2017 & Turma 2018 & Turma 2019 & Total \\
\hline Barra Mansa & 0 & 1 & 1 & 2 \\
\hline Engenheiro Paulo de Frontim & 0 & 0 & 1 & 1 \\
\hline Itaguaí & 0 & 1 & 1 & 2 \\
\hline Japeri & 1 & 2 & 0 & 3 \\
\hline Miguel Pereira & 1 & 0 & 0 & 1 \\
\hline Nova Iguaçu & 3 & 2 & 3 & 8 \\
\hline Paraty & 0 & 1 & 0 & 1 \\
\hline Paty do Alferes & 0 & 0 & 1 & 1 \\
\hline Piraí & 0 & 1 & 0 & 1 \\
\hline Quatis & 1 & 0 & 0 & 1 \\
\hline Resende & 0 & 2 & 0 & 2 \\
\hline Rio de Janeiro & 2 & 5 & 9 & 16 \\
\hline Seropédica & 0 & 18 & 18 & 4 \\
\hline Volta Redonda & 0 & 0 & 5 \\
\hline Total & & 2 & 18 & \\
\hline
\end{tabular}

Fonte: SIGAA-UFRRJ (Programa de Pós-Graduação em Matemática em Rede Nacional) 


\section{Municípios do Estado do Rio de Janeiro}

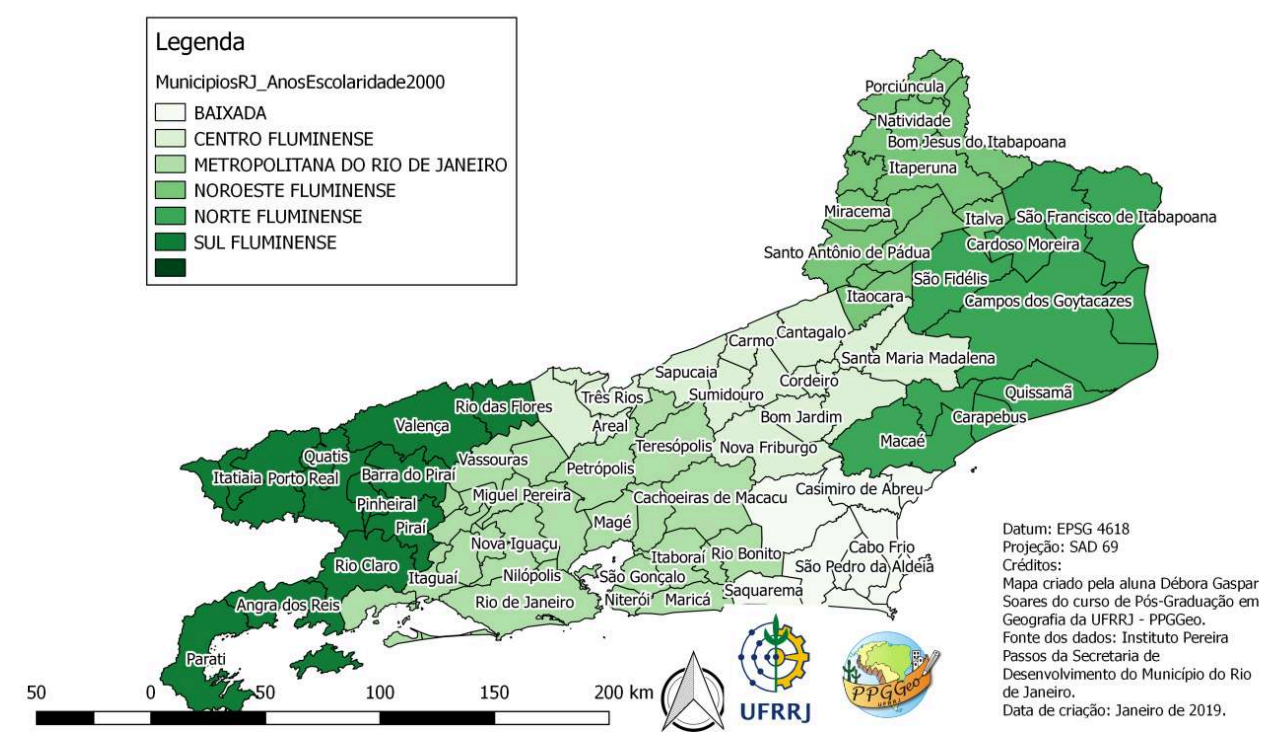

Fonte: Instituto Pereira Passos.

A estrutura do PROFMAT no polo da Universidade Federal do Rio de Janeiro é o local de funcionamento presencial do curso, o lugar físico onde ocorrem as aulas, e se encontram o aluno, tutor, professor, coordenação e outros agentes de conhecimento. $O$ polo do PROFMAT-UFRRJ que coordena os sistemas e a infraestrutura que viabilizam as interações e os fluxos de informações. Apesar, do PROFMAT exigir o encontro presencial com os alunos uma vez por semana, o PROFMAT depende que a instituição polo ofereça laboratório de informática para os alunos, porque a proposta pedagógica primazia pela utilização da Plataforma Moodle de Educação, e é nesse ambiente virtual de aprendizagem que se disponibiliza os fóruns, chats, webconferências, troca de mensagens, as disciplinas, as redes de comunicação, as vídeo-aulas (não foi encontrado o tempo de atualização desse material), e material didático, que só podem ser acessados pela internet, portanto configura a dependência desse modelo educacional às tecnologias informacionais em rede. De acordo com Damiani (2016, p.14): “a era urbana real e utópica, ao mesmo tempo, é a superação da crise implicada na separação campocidade. Ela identifica um elemento novo: a programação do consumo, a manipulação das necessidades, através do cotidiano; trata-se da cotidianidade." Em conformidade Heller (2016 [1970], p.30) afirma: "Na maioria das formas de atividade da vida cotidiana, as motivações do homem não chegam a se tornar típicas, ou seja, as motivações em permanente alteração estão muito longe de expressar a totalidade, a essência do indivíduo." Já Lefebvre (1991, p.23) destaca que: "O homem cotidiano se fecha em suas propriedades, seus bens e suas satisfações, e às vezes se arrepende. Ele está ou parece estar mais próximo da natureza do que o sujeito da reflexão ou, da cultura." Os autores discutem sobre a alienação propiciada pela sociedade informacional, e pelo modo de produção capitalista, no quanto essa se alastra para além do cotidiano, para a própria ciência contemporânea, para os modelos educacionais, e sobre os fundamentos e estruturas da vida cotidiana. 

matriculados.

\section{Fluxo de informações do polo PROFMAT- UFRRJ}

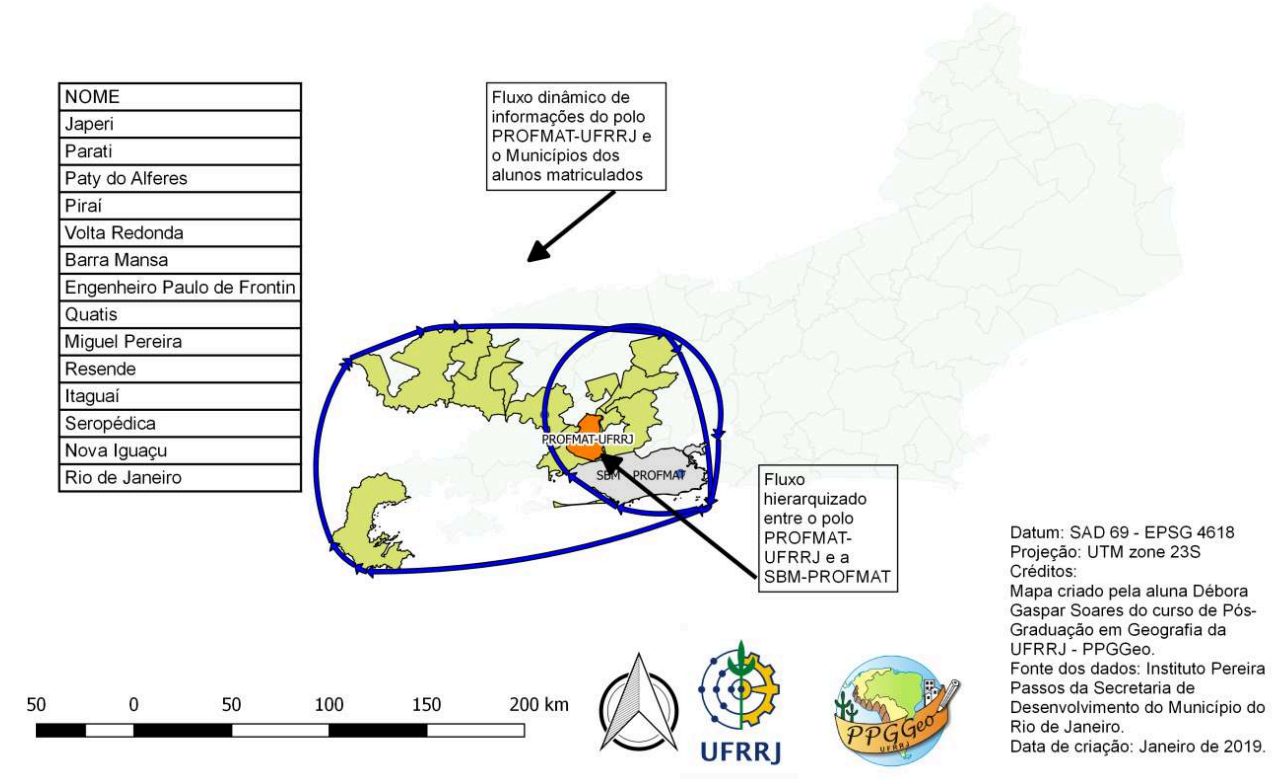

Fonte: Instituto Pereira Passos.

O PROFMAT, ao tornar-se adepto da EaD, adotou a modalidade semipresencial que busca conciliar as práticas pedagógicas virtuais e presenciais do aluno. Na Plataforma Moodle, o aluno dispõe das vídeo-aulas, material didático, guias, e as distintas redes de comunicação com Professor e Tutor à distância, assim configurando as ações do aluno em rede. Mas, esse território virtual de ensino possibilita o encontro presencial, no qual o aluno é acompanhado pelo Professor, o Tutor é à distância, que acaba sendo mediador e orientador das atividades na Plataforma e no polo. Nesse sentido, o relatório digital do PROFMAT 2017 sinaliza que a oferta da formação de Professores de Matemática na EaD enfrenta adversidades, reveses e diversos desafios relacionados a sociedade informacional. Vale destacar que essa oferta do curso está sujeita a exclusão de outros extratos sociais, a completa retração e restrição de vagas de demanda social conforme comunicado PROFMAT № 01/2019 de que as vagas para o processo de seleção PROFMAT/2020 são exclusivas para docentes do ensino básico das redes públicas, devido a uma nova interpretação da Portaria CAPES №209 de 21 de outubro de 2011. Assim, os alunos do PROFMAT, que até o presente momento são na maioria professores do ensino básico, e que devem se tornar exclusivos do ensino básico das redes públicas, e cuja formação educacional e exercício laboral são alicerçados pela modalidade presencial. Nesse sentido, compreende-se que o seu processo histórico, memória, e formas de aprendizado seguem referências pedagógicas no contato físico, e direto aluno-professor em sala de aula. Então, o conteúdo do PROFMAT necessita desenvolver competências e habilidades na utilização e ações na EaD, para que esse professor tenha competência de transformar o seu método de aprendizagem, e acrescentar novos recursos informacionais para sala de aula e para a escola, sendo que os conteúdos 
oferecidos são específicos da Matemática, e a única disciplina caracterizada como Humano-Digital: Recursos Computacionais para o Ensino de Matemática é eletiva.

Nessa conjuntura, o tutor à distância no PROFMAT-UFRRJ apresenta relevância, porque esse é responsável pelo contato virtual, por implementar estratégias que promovem a aprendizagem colaborativa na Plataforma Moodle, como formação de grupos de estudos, chats, fóruns de conversa além da disciplina, seu desempenho como sujeito motivador, orientador e mediador da rede de comunicação. Conforme exposto, o PROFMAT não exige formação de Tutores em EaD para os professores do curso, e isso tem reflexo no curso, especialmente para o exercício de construção coletiva do conhecimento. Segundo a Coordenação anterior do PROFMAT-UFRRJ:

"Olha para a gente aqui, a gente está pensando em repensar essa figura do tutor, porque ultimamente ele está sendo pouco utilizado, é, então isso, até porque os alunos também estão utilizando pouco esse ensino a distância, na realidade, aliás, ou seja, ele usa, mas ele está estudando isso, estudando de forma mais individualizada, mais de cunho entre eles mesmos, e acaba que o tutor está sendo pouco utilizado."

20 Em conformidade, a Coordenação atual do PROFMAT-UFRRJ, declara:

"Enfim, o que aconteceu à medida que o tempo foi passando, como o PROFMAT tem um caráter semipresencial, é, o que a gente viu no programa é que a função do tutor, acabou, é quase tendo uma função presencial mesmo. Com a plataforma, ela está sendo, assim, mais utilizada para fins do aluno consultar uma vídeo-aula, pegar um material, uma lista de exercícios, mas não está sendo usada para tirar dúvidas, os alunos estão preferindo tirar dúvidas com o tutor e o professor pessoalmente. Hoje em dia o tutor está mais com uma função de auxiliar o professor."

21 Sob outra perspectiva, os encontros presenciais, no qual se realiza o contato direto com o aluno na UFRRJ, representa uma tática pedagógica eficiente de redução de evasão do PROFMAT. Na sala de aula se estabelece o contato físico, no polo se conecta os diversos fluxos de informação de todos os agentes de conhecimento que participam da rede de comunicação. O delineamento dos contatos tanto virtual como o físico representa as teias de relações tanto entre os sistemas e técnicas sócio espaciais, compondo e constituindo um ordenamento territorial virtual. Em conformidade com Heller (2016 [1970], p.32): “é indiscutível que uma ação correspondente aos interesses de uma classe ou camada pode se elevar ao plano da praxis, mas nesse caso superará o da cotidianidade; a teoria da cotidianidade, nesses casos, converte-se em ideologia." A autora esclarece que a cotidianidade é imbuída de circunstâncias que oportunizam o desenvolvimento humano-genérico, como o pensamento teórico, ela explica que a teoria e a práxi intervêm em finalidades e conteúdos que na realidade caracterizam o humano-genérico.

22 Contrapondo a relação dos alunos matriculados no PROFMAT-UFRRJ (2017-2019), verifica-se que os municípios de Nova Iguaçu, Rio de Janeiro e Volta Redonda, mantiveram ou ampliaram sua matrícula no polo, isso indica que houve uma divulgação, repercussão, e procura do curso pelos outros profissionais, ou seja, que há interesse pelos professores de Matemática em se capacitar no modelo EaD. Essa inserção social é relatada no Relatório Digital do PROFMAT 2017, que relata dados de um formulário respondido pelos alunos, professores e coordenadores, em que os egressos afirmam que a formação ajudou no seu desempenho profissional como maior segurança para apresentar conteúdos, habilidade para motivarem os alunos pelo conteúdo, e maior capacidade de elaboração de material didático. Outro fator relevante 
é que o egresso considera o curso importante no avanço da sua carreira profissional. 0 Relatório Digital do PROFMAT (2017, p.34) destaca: "considera-se haver uma mudança na postura e na prática da sala de aula, tendo consequentemente contribuído para a melhoria da Educação Básica, seu principal objetivo." Para finalizar, há apenas um indicador nesse material de pertinência sócio espacial que é o aumento do envolvimento dos egressos na preparação e motivação da participação dos alunos da Educação Básica na Olimpíada Brasileira de Matemática. De acordo com Heller (2016 [1970], p.32): "o precedente tem mais importância para o conhecimento da situação que para o conhecimento das pessoas. É um "indicador" útil para nosso comportamento, para nossa atitude." A autora elucida que as relações sociais se degeneram conforme os sistemas funcionais da sociedade informacional geram estereótipos, vidas estereotipadas, imitação, no ofício das circunstâncias sociais de domínio, manipulação, e os comportamentos configuram-se em papéis cerceando a individualidade.

\section{Considerações Finais.}

A observação das informações relativas ao PROFMAT, correlacionadas a demanda sobre sua institucionalização no ambiente do polo da UFRRJ, apresenta indicativos para buscar entender o uso da modalidade $\mathrm{EaD}$ para promoção e formação técnico-científica de Professores de Matemática do ensino básico. Não há dúvidas que a modalidade EaD se tornou, no âmbito educacional, uma modalidade de ensino substancial e permanente, que é fomentada pela sociedade informacional capitalista. Tal condição assente significância porque exige práticas pedagógicas mais avançadas e em conformidade com a vida cotidiana midiática, tecnológica e em rede atual. Entretanto, a oferta dessa formação de Mestrado e a inserção social desses professores de Matemática na Universidade revelam desigualdades sócio espaciais. Apesar da conexão em rede de distintos municípios, a hierarquização e sistematização do EaD cerceia a prática pedagógica; a escolha e determinação dos conteúdos a serem apresentados pelos Tutores a distância impede a autonomia de preparação pedagógica, e a falta de exigência da formação em Tutores em EaD para os professores do PROFMAT dificulta a função de mediador na Plataforma Moodle; a comunicação ser pela Plataforma Moodle limita a liberdade de expressão e o pensamento crítico dos agentes de conhecimento. De acordo com Heller(2016 [1970], p.32): "as formas necessárias da estrutura e do pensamento da vida cotidiana não devem se cristalizar em absolutos, mas têm de deixar ao indivíduo uma margem de movimento e possibilidades de explicitação." Em conformidade Silva $(2008$, p.8) elucida: "o crítico está impresso nas formas de produção e reprodução do urbano, bem como o seu produto final: um espaço posto como valor de troca [...] e o aprofundamento dos processos de segregação urbana." Esses autores explicitam que o modelo do EaD de construção colaborativa de conhecimento fomentado pelo capitalismo neoliberal elabora conhecimentos que não se propõem a esclarecer a prática da vida cotidiana, nem são capazes de responder a complexidade humana.

24 A geografia que está sendo delineada e tecida por meio do ordenamento territorial virtual representa um desafio para esse estudo do PROFMAT, os dados do polo presencial da UFRRJ sugerem como a rede projeta esse território virtual de práticas pedagógicas. Quanto à promoção de ciência, tecnologia, técnica, conteúdo, e informação, há a ausência de uma definição da CAPES do conceito de inovação que deve 
ser utilizado, ainda assim, a rede dinamiza esse território virtual e conecta os agentes de conhecimento. Nessa acepção, o polo presencial da UFRRJ equivale à zona de conexão entre os fluxos de informação e agentes de conhecimento que utilizam a rede de comunicação do PROFMAT. O ponto de partida para a formação do ordenamento territorial virtual se esboça na articulação desses centros urbanos, que arquitetam suas relações e contatos através da rede, essas configuram formas e sistemas sócio espaciais, autossuficiente da dimensão física e alcance do local, ignorando o modelo tradicional capitalista de urbanização. Nessa cinesia de ordenamento territorial virtual sobrevém a ressignificação das concepções de próximo e distante, e toda a topologia da rede é fechada, é tecida na área de interação entre conteúdo-rede, zona-conexão e virtualização-plataforma, que edifica uma teia de articulações da contemporânea sociedade informacional. Em conformidade com Lukács (2003, p.216): "surge uma sistematização racional de todas as regulamentações jurídicas da vida, sistematização que representa pelo menos em sua tendência, um sistema fechado e que pode se relacionar com todos os casos possíveis e imagináveis." o autor explica que o modelo EaD de aprendizagem colaborativa, como território virtual é um sistema fechado que ojeriza e produz um abismo para ação do pensamento crítico, do reflexivo, do que reproduz a vida cotidiana, do familiar, do habitual, do ordinário, dos que são desconsiderados cientificamente, ou tecnicamente, ou ideologicamente.

Para perfazer esse estudo, a formação dos professores de Matemática necessita repensar a formação para o trabalho em educação. Simplesmente, porque analisando o relatório digital do PROFMAT 2017, há apenas um indicador sócio espacial destacado que é o aumento da participação dos alunos do ensino básico na Olimpíada Brasileira de Matemática. Apesar do relatório possuir um capítulo denominado "Inserção social", não está claro de que se trata nem qual extrato social alcança e transforma, pois não há uma definição de que e qual inserção social tanto da SBM, como do IMPA, como do CNPq, como da CAPES. O território virtual de rede de comunicação é baseado pela conexão e interação, e nessas condições não há dados que esclareçam como o uso e difusão da rede na formação de Professores reverbera no ordenamento escolar das cidades desses professores. Aprendizagem se constrói absolutamente por meio do diálogo, do debate, da comunicação, e a formação para o trabalho não deve dominar as vozes, as elocuções, as reflexões, o território virtual para a prática pedagógica não deve ser um sistema fechado, hierarquizado, é necessário para a educação, para o trabalho, para vida cotidiana a autonomia. Em concordância com Barthes (1977, p.9): "quanto mais livre for esse ensino, tanto mais será necessário indagar-se sob que condições e segundo que operações o discurso pode despojar-se de todo desejo de agarrar." Diante desse panorama, é crucial para a sociedade informacional uma tomada de atitude, a prática pedagógica não pode constituir como ameaça para a sociedade, é vital para função e exercício de professorar o reconhecimento dessas conjunturas, é imprescindível que a educação no território virtual quer seja no espaço da universidade, quer seja no espaço da escola pública seja oportuna, propícia e favorável para a reflexão sobre os planos, programas e concepções sociais que pretenda edificar.

\section{AGRADECIMENTOS}

Agradeço imensamente a Deus por esse trabalho. 
27 Agradeço a assistência, a fundamentação e a inspiração recebida pela Pós-graduação em Geografia, a toda equipe, aos meus caros colegas, especialmente a organização, atenção e o zelo dos Coordenadores Clézio dos Santos e Márcio Rufino.

28 Agradeço o apoio recebido pelo grupo de Iniciação Científica: Educação e Mundo Contemporâneo (UFRRJ), a todas as discussões e questionamentos que fizeram parte da nossa amizade, e o respeito e admiração que tenho por cada um de vocês colegas. Estendo esses agradecimentos a Professora Lúcia Sartório e ao meu orientador Professor Márcio Rufino pela direção, pelas orientações, pela presença a cada momento desse trabalho e o inestimável apoio intelectual.

29 Agradeço a contribuição material da Universidade Federal Rural do Rio de Janeiro (UFRRJ) que ofereceu esse projeto, a CAPES, a FAPERJ, ao CNPq, a Universidade Federal do Rio de Janeiro (UFRJ), a Universidade Estadual do Rio de Janeiro (UERJ), a Universidade Federal Fluminense (UFF), a Sociedade Brasileira de Matemática (SBM) e a Fundação CECIERJ (CEDERJ).

30 Agradeço à ajuda recebida, na pesquisa bibliográfica, dos professores Giuseppe Cocco e Sarita Albagli do PPGCI/IBICT-UFRJ, ao Bruno Tarin, a todos os colegas, ao IBCT, ao LIINC e ao PPGCI. A compreensão, generosidade e a atenção do Professor Orlando Pereira, da Professora Aline Barbosa, e da Professora Rosane de Oliveira, e a toda equipe do DEMAT da UFRRJ. Como também à ajuda recebida, na pesquisa de campo, dos professores José Augusto Sapienza e Victor Valentim do LABGIS-UERJ.

31 Agradeço a cada um dos meus professores que ao longo da minha vida foram pacientes comigo e por me educarem. Acrescento a cada um dos meus amigos, aos colegas, aos funcionários e a todos que de alguma forma me ajudaram em algum momento.

32 Agradeço a minha família, em especial a minha mãe Célia e ao meu pai Daniel por serem minhas raízes, as minhas irmãs Daniela e Diane por me incentivarem sempre, aos meus \sobrinhos Maria Clara e João Vitor por me cativarem tanto amor, aos meus cunhados Anderson e Alex por me ajudarem incondicionalmente. E a todos os meus familiares, os meus amigos familiares, e a minha comunidade neocatecumenal pela cooperação.

33 Agradeço ao meu marido Ivan por me apoiar de forma extraordinária, por todos os seus questionamentos desse trabalho, por ser um grande professor, por quem tenho profunda admiração pelo seu trabalho de excelência e seu amor ao magistério. Acrescento ao meu filho Daniel que torna o meu dia feliz por acordar sorrindo todos os dias.

Muito obrigada!

\section{BIBLIOGRAFIA}

BAITZ, Ricardo. Implicação: um novo sedimento a se explorar na Geografia? In: Boletim Paulista de Geografia, no 84, jul. 2016, pp. 25-50. 
BARTHES, Roland. Aula. 15ª ed. São Paulo: Cultrix (2007 [1978]).

DAMIANI, Amélia Luísa (coord.) et. al. o futuro do trabalho : elementos para a discussão das taxas de maisvalia e de lucro. São Paulo: AGB/SP. Labur/Programa de Pós-Graduação em Geografia Humana, Departamento de Geografia, FFLCH/USP, 2006. 72 p.

LEFEBVRE, Henri. Prefácio - A produção do espaço. Estudos Avançados (USP), vol. 27, n.79, set/ $\operatorname{dez}(2013$ [1985]).

HAESBAERT, Rogério. Regional-Global: dilemas da região e da regionalização na geografia contemporânea. Rio de Janeiro: Bertrand Brasil (2010).

HELLER, Agnes. O cotidiano e a história. 11ª ed. Rio de Janeiro: Paz e Terra, 2016 [1970].

LATOUR, Bruno. Ciência em ação. Como seguir cientistas e engenheiros sociedade afora. São Paulo: Unesp (2000 [1998]).

MINISTÉRIO DA EDUCAÇÃO. Portaria nº4059, Art. 1, §1, Brasília, 2004.

MINISTÉRIO DA EDUCAÇÃO. Indicadores de qualidade para cursos de graduação a distância, Brasília, 2000, p.4).

PROFMAT. Disponível em < http://www.profmat-sbm.org.br/>. Acesso em 08/01/2019.

\section{RESUMOS}

o cenário da universidade em âmbito nacional tem experimentado alterações no seu espaço educacional derivadas de diferentes fatores, entre os quais compete destacar a implantação de Novas Tecnologias de Informação e Comunicação na prática docente. Esse estudo, busca a análise dessas mudanças que são fomentadas pelo Sistema Nacional de Inovação que orienta a CAPES, a FAPERJ, e o CNPq, na perspectiva da Teoria de Agnes Heller, na introdução sistemática de recursos inovativos nas atividades docentes em concordância com as exigências neoliberais e as mudanças que essas impõem ao exercício do professor, especialmente na construção do cotidiano em territórios virtuais, e na sua jornada de trabalho, dissuadindo os objetivos, a organização e a finalidade da educação.

Le scénario universitaire au niveau national a connu des changements dans son espace éducatif découlant de différents facteurs, parmi lesquels il est important de souligner la mise en œuvre des nouvelles technologies de l'information et de la communication dans la pratique de l'enseignement. Cette étude cherche à analyser ces changements favorisés par le système national d'innovation qui guide le CAPES, le FAPERJ et le CNPq, du point de vue de la théorie d'Agnès Heller, dans l'introduction systématique de ressources innovantes dans les activités d'enseignement, conformément aux exigences néolibérale et les changements que ceux-ci imposent à l'exercice de l'enseignant, en particulier dans la construction de la vie quotidienne dans des territoires virtuels et dans leur journée de travail, dissuadant ainsi les objectifs, l'organisation et le but de l'éducation.

El escenario universitario a nivel nacional ha experimentado cambios en su espacio educativo derivado de diferentes factores, entre los cuales es importante destacar la implementación de nuevas Tecnologías de Información y Comunicación en la práctica docente. Este estudio busca analizar estos cambios impulsados por el Sistema Nacional de Innovación que guía a CAPES, FAPERJ y CNPq desde la perspectiva de la Teoría de Agnes Heller, en la introducción sistemática de recursos innovadores en actividades de enseñanza de acuerdo con los requisitos neoliberales y cambios que estos imponen en el ejercicio del maestro, especialmente en la construcción de la 
vida diaria en territorios virtuales, y en su jornada laboral, disuadiendo los objetivos, organización y propósito de la educación.

The university scenario at the national level has experienced changes in its educational space derived from different factors, among which it is important to highlight the implementation of new Information and Communication Technologies in teaching practice. This study seeks to analyze these changes that are fostered by the National Innovation System that guides CAPES, FAPERJ, and CNPq, from the perspective of Agnes Heller's Theory, in the systematic introduction of innovative resources in teaching activities in accordance with the requirements neoliberal and the changes that these impose on the exercise of the teacher, especially in the construction of daily life in virtual territories, and in their work day, dissuading the objectives, organization and purpose of education.

\section{ÍNDICE}

Mots-clés: territoires virtuels, vie quotidienne, formation au travail, éducation à distance.

Palavras-chave: territórios virtuais, cotidiano, formação para o trabalho, Educação à Distância. Keywords: virtual territories, daily life, training for work, Distance Education.

Palabras claves: territorios virtuales, vida cotidiana, formación para el trabajo, educación a distancia.

\section{AUTORES}

\section{DÉBORA GASPAR SOARES.}

Mestranda da Pós-Graduação em Geografia da Universidade Federal Rural do Rio de Janeiro. Membro do grupo de pesquisa: Para uma crítica da Economia Política do Espaço, do(a) Universidade Federal Rural do Rio de Janeiro. (deboragirassol@gmail.com)

\section{MÁRCIO RUFINO SILVA.}

Doutor em Geografia Humana pela USP. Professor Adjunto na Universidade Federal Rural do Rio de Janeiro. (marciorufis@gmail.com) 